\title{
PREVALENSI KOMPONEN SINDROM METABOLIK PADA PEGAWAI BUMN PT WIJAYA KARYA DIVISI IV SURABAYA
}

\section{The Prevalence of Metabolic Syndrome Component Among BUMN Workers in PT Wijaya Karya Division IV Surabaya}

\author{
Ulinnuha Qurrota A'yunin*1 . Endang Retnowati². Jongky Hendro Prayitno ${ }^{3}$ \\ ${ }^{1}$ Program Studi Pendidikan Dokter, Universitas Airlangga Surabaya, Indonesia \\ ${ }^{2}$ Departemen Patologi Klinik Fakultas Kedokteran Universitas Airlangga, Indonesia \\ ${ }^{3}$ Departemen Ilmu Penyakit Dalam Pusat Diabetes dan Nutrisi Fakultas Kedokteran Universitas Airlangga
}

Diterima: 16 Maret 2019; Revisi: 19 Juni 2019; Diterbitkan: 29 Juli 2019

\section{ABSTRACT}

Background: Metabolic syndrome is a group of risk factors that appear together as a combination of the rising of blood glucose level, the abnormalities of lipid profile, high blood pressure, and central obesity. The prevalence of metabolic syndrome among workers in Indonesia is $24.4 \%$ and tend to rise in relatively young age workers. Someone could be said having a metabolic syndrome when they have minimal three from five criteria from NCEP ATP III. The purpose of this study is to know the prevalence of metabolic syndrome among workers. Design: A descriptive study of 70 workers who participated in the annual health examinations was conducted by PT Wijaya Karya Division IV Surabaya during the period of October 2016. The variable which analyzed includes the prevalence of metabolic syndrome, its component, age, sex, and working location. Results of this study were presented in a frequency distribution table. Result: The prevalence of metabolic syndrome among workers is $22.1 \%$ with the highest gender is male (93.3\%) and the largest age group is $31-40$ years old (33.3\%). Most case of metabolic syndrome has three component $(66.7 \%)$ with the sequence from the most to the least common are hypertriglyceridemia $(35.5 \%)$, high blood pressure $(32.4 \%)$, low HDL cholesterol $(26.5 \%)$, hyperglycemia $(23.5 \%)$, and abdominal circumference $(21.3 \%)$. The prevalence is higher in office located workers $(66.7 \%)$ than field located workers. Conclusion: The prevalence of metabolic syndrome among workers is $22.1 \%$ which shows more than one fifth of workers population have serious health problems that should be followed up.

Key words: prevaalence, metabolic syndrome, workers,

\section{ABSTRAK}

Latar Belakang: Sindrom metabolik merupakan sekumpulan faktor risiko yang ditemukan muncul bersamaan yakni perpaduan antara adanya kenaikan kadar glukosa darah, abnormalitas profil lemak, tekanan darah tinggi, dan obesitas abdomen. Prevalensi sindrom metabolik pada pegawai di Indonesia sebesar $24,4 \%$ dan cenderung meningkat terutama pada usia pekerja yang relatif muda. Seseorang dapat dikatakan menderita sindrom metabolik apabila memilik minimal tiga dari lima kriteria yang dikeluarkan oleh NCEP ATP III. Tujuan penelitian ini adalah untuk mengetahui prevalensi komponen sindrom metabolik pada para pegawai dan diharapkan dapat menjadi data awal dalam upaya pencegahan dan pengobatan. Metode: Penelitian deskriptif terhadap 70 pekerja yang berpartisipasi dalam pemeriksaan kesehatan tahunan dilakukan oleh PT Wijaya Karya Divisi IV Surabaya periode Oktober 2016. Variabel yang dianalisis meliputi prevalensi sindrom metabolik, komponen, usia, jenis kelamin, dan pekerjaan lokasi. Data yang didapat kemudian dipaparkan dalam tabel distribusi. Hasil: Pada penelitian ini didapatkan bahwa prevalensi sindrom metabolik pada pegawai adalah $22.1 \%$ dengan laki - laki sebagai jenis kelamin terbanyak (93.3\%) dan kelompok usia terbanyak adalah 31 - 40 tahun (33.3\%). Pekerja di dalam kantor memiliki prevalensi lebih besar $(66.7 \%)$ daripada pekerja lapangan. Jumlah penanda sindrom metabolik yang terbanyak sindrom metabolik ditemukan adalah 3 penanda (66.7\%) dengan urutan dari yang terbanyak ditemukan adalah kadar trigliserida (35.5\%), tekanan darah (32.4\%), kadar kolesterol HDL (26.5\%), kadar glukosa darah puasa (23.5\%) dan lingkar perut (21.3\%). Kesimpulan: Prevalensi sindrom metabolik di kalangan pekerja adalah $22,1 \%$ yang menunjukkan lebih dari seperlima populasi pekerja memiliki masalah kesehatan serius yang harus ditindaklanjuti.

Kata kunci : prevalensi, sindrom metabolik, pegawai

*Korespondensi: Ulinnuha Qurrota A’yunin, email: ayunin_spensa@yahoo.com

DOI : $10.22487 / \mathrm{j} 26227622.2019 . v 3.11 .12117$ 


\section{PENDAHULUAN}

Metabolic syndrome atau sindrom metabolik merupakan kumpulan faktor risiko yang dapat meningkatkan risiko terjadinya penyakit kardiovaskular, diabetes, stroke, dan masalah kesehatan lainnya (American Heart Association, 2015). International Diabetes Federation, Federation (2005) menyatakan bahwa sindrom metabolik adalah sekumpulan faktor risiko yang sering ditemukan muncul bersamaan yakni perpaduan antara adanya kenaikan kadar gula darah, abnormalitas profil lemak, tekanan darah tinggi, dan obesitas abdomen. Dari data epidemiologi disebutkan bahwa prevalensi sindrom metabolik di dunia adalah sebesar $20-25 \%$ (Federation, 2005). Populasi Asia Selatan yang dilaporkan karena prevalensi yang tinggi untuk penderita sindrom metabolik memiliki kecenderungan tinggi yang tidak biasa untuk berkembang menjadi diabetes melitus tipe dua (T2DM) dan penyakit jantung koroner (PJK) (Misra et al., 2006). Prevalensi sindrom metabolik yang ditetapkan menggunakan kriteria ATP III pada 13.304 orang dewasa di Kavar Iran Selatan ditemukan sebesar $25,1 \%$ dengan prevalensi pada pada perempuan lebih tinggi dibanding laki - laki, yakni $28,4 \%$ pada perempuan dan $18,9 \%$ pada laki - laki $(\mathrm{p}<0.001)$ dan prevalensi juga meningkat seiring bertambahnya usia $(p<0,001)$ (Karimi et al., 2015). Gami et al. (2007) menyatakan bahwa risiko terkena penyakit kardiovaskular menjadi dua kali lebih besar pada penderita sindrom metabolik daripada yang tidak ditemukan tanda sindrom metabolik dan Lorenzo et al. (2003) menyatakan bahwa penderita sindrom metabolik memiliki kemungkinan terkena penyakit diabetes sebesar $30-$ $40 \%$.

Prevalensi sindrom metabolik dikalangan pekerja saat ini juga cenderung miningkat (Zahtamal, Prabandari, \& Setyawati, 2016). Penelitian oleh Semiardji (2004) menyatakan bahwa $24,4 \%$ penyakit di kalangan pekerja adalah penyakit yang terkait oleh kriteria sindrom metabolik. Hal ini bisa dikarenakan rendahnya pengetahuan pekerja tentang tanda - tanda sindrom metabolik ini sendiri maupun kurangnya penyuluhan petugas kesehatan tentang bahaya akumulasi tanda - tanda sindrom metabolik dalam tubuh. Di Indonesia prevalensi sindrom metabolik pada pekerja perusahaan sebanyak $21,58 \%$, dengan laki - laki sebagai jenis kelamin terbanyak dan $>50$ tahun sebagai kelompok usia terbanyak yang ditemukan (Zahtamal, Prabandari, \& Setyawati, 2016). Menurut Zahtamal, Prabandari, \& Setyawati (2016), dari hasil data yang diperoleh, lingkar perut dan tekanan darah adalah komponen terbanyak yang ditemukan dari kriteria sindrom metabolik dan sebanyak 23,50\% kasus memiliki kriteria diabetes melitus serta obesitas sebagai riwayat keluarga, sedangkan untuk kategori aktivitas sebagian besar adalah sedang dan jenis asupan yang yang tinggi lemak jenuh. Dampak buruk sindrom metabolik sebagai penyakit degeneratif pada para pekerja merupakan kerugian yang sangat besar untuk perusahan dengan perkiraan lebih dari US\$ 2,8 triliun setiap tahunnya (International Labour Organization, 2013).

Seseorang dapat dikatakan menderita sindrom metabolik apabila memilik tiga dari lima kriteria yang dikeluarkan oleh National Cholesterol Education Program's Adult Treatment Panel III (2001), yaitu obesitas sentral yang diukur melalui lingkar perut 102 centimeter untuk laki - laki Asia dan $\geq 88$ centimeter untuk perempuan Asia, trigliserida $\geq 150 \mathrm{mg} / \mathrm{dL}$ atau sedang dalam terapi spesifik untuk lemak abnormal, kolesterol high density lipoprotein (HDL) $<40 \mathrm{mg} / \mathrm{dL}$ pada pria dan $<50 \mathrm{mg} / \mathrm{dL}$ pada wanita atau sedang dalam terapi spesifik untuk lemak abnormal, tekanan darah sistolik/diastolik $\geq 130 / 85 \mathrm{mmHg}$, dan gula darah puasa $\geq 100 \mathrm{mg} / \mathrm{dL}$ atau pernah didiagnosa mengidap diabetes melitus tipe 2 .

Penyebab yang mendasari terjadinya sindrom metabolik menurut International Diabetes Federation (Federation, 2005) masih belum dapat ditentukan namun beberapa hipotesis menganggap obesitas sentral dan resistensi insulin sebagai faktor yang signifikan. Beberapa faktor dari sisi pekerja yang diduga memberi kontribusi terhadap munculya sindrom metabolik, diantaranya perilaku sedenter (tidak banyak aktivitas fisik atau terlalu banyak duduk), pola makan tidak sehat, kebiasaan merokok, stress, usia, dan lain lain. Menurut hasil penelitian Hildrum et al. (2007) prevalensi sindrom metabolisme berdasar kriteria IDF meningkat pada laki - laki dari $11,0 \%$ pada kelompok usia 20 - 29 tahun menjadi $42,7 \%$ pada kelompok $80-89$ tahun, dan dari 9,2\% menjadi $64,4 \%$ pada wanita dengan kelompok usia yang sama. Hildrum et al. (2007) juga menyatakan bahwa dengan usia $\geq 60$ tahun ditemukan mengidap obesitas sebesar $56,7 \%$ pada laki - laki dan $75,0 \%$ pada wanita, tekanan darah darah tinggi juga ditemukan sebesar $89,3 \%$ pada laki - laki dan 90,9\% pada wanita.

Berdasarkan latar belakang tersebut, penelitian ini bertujuan untuk memaparkan jumlah keseluruhan kasus sindrom metabolisme dan distribusi komponen sindrom metabolik pada pegawai BUMN PT Wijaya Karya periode Oktober 2016 usia 30 - 60 tahun

\section{BAHAN DAN METODE}

Jenis penelitian ini adalah studi deskriptif kuantitatif dengan menggunakan data sekunder yang bersumber dari data Dokumen Medik Kesehatan (DMK) hasil pemeriksaan kesehatan pegawai BUMN PT Wijaya Karya Divisi IV Surabaya periode Oktober 2016. Populasi yang diteliti dalam penelitian ini adalah pegawai BUMN PT Wijaya Karya Divisi IV Surabaya usia $20-60$ tahun yang mengikuti pemeriksaan kesehatan periode Oktober 2016. Besar sampel penelitian ini menggunakan total sampling pegawai BUMN PT Wijaya Karya Divisi IV Surabaya usia 20 60 tahun yang mengikuti pemeriksaan kesehatan periode Oktober 2016. Total sampling adalah teknik pengambilan sampel dimana jumlah sampel sama dengan populasi (Sugiyono, 2007). Penelitian ini menggunakan teknik total sampling karena menurut Sugiyono (2007) jumlah sampel yang kurang dari 100, seluruh populasi dijadikan sampel penelitian semuanya.

Data yang dikumpulkan berupa usia, lingkar perut, tekanan darah, kadar trigliserida, kadar kolesterol HDL, dan kadar glukosa darah puasa. Kemudian data tersebut dipindahkan ke lembar pengumpulan data untuk dikelola mengunakan program Excel Microsoft for Windows. 


\section{HASIL}

Tabel 1 menyatakan bahwa jumlah pegawai BUMN PT Wijaya Karya Divisi IV Surabaya yang termasuk dalam kategori sindrom metabolik sebanyak 15 orang $(22.1 \%)$, sedangkan pegawai yang termasuk dalam kategori bukan sindrom metabolik mencakup sisanya, yaitu sebanyak 53 orang $(77.9 \%)$.

Tabel 1. Prevalensi Sindrom Metabolik pada Pegawai

\begin{tabular}{lll}
\hline Kategori & $\mathrm{n}$ & $\%$ \\
\hline Sindrom Metabolik & 15 & 22,1 \\
Bukan Sindrom Metabolik & 53 & 77,9 \\
\hline
\end{tabular}

Tabel 2 menjelaskan tentang deskriptif individu penelitian yang mengidap sindrom metabolik, hasil analisis dapat disimpulkan bahwa sebagian besar pegawai berumur $31-40$ tahun dan berjenis kelamin perempuan $(93.3 \%)$; dengan lokasi pekerjaan di dalam kantor $(66.7 \%)$; tiga penanda sindrom metabolik $(66.7 \%)$.

Tabel 2. Karakteristik Pegawai dengan Sindrom Metabolik

\begin{tabular}{lll}
\hline Variabel & $\mathbf{n}$ & $\mathbf{\%}$ \\
\hline Jenis kelamin & & \\
$\quad$ Laki - laki & 1 & 67 \\
$\quad$ Perempuan & 14 & 93.3 \\
Lokasi pekerjaan & & \\
$\quad$ Kantor & 10 & 66.7 \\
$\quad$ Lapangan & 5 & 33.3 \\
Jumlah penanda sindrom metabolik & & \\
3 penanda & 10 & 66.7 \\
4 penanda & 5 & 33.3 \\
5 penanda & 0 & 0 \\
\hline
\end{tabular}

Pada tabel 3 dapat disimpulkan distribusi penanda sindrom metabolik yaitu lingkar perut $\geq 88$ $\mathrm{cm}$ pada pegawai perempuan sebesar $3.1 \%$ dan $\geq 102$ $\mathrm{cm}$ pada pegawai laki - laki sebesar 18.2\%; kadar trigliserida pegawai $\geq 150 \mathrm{mg} / \mathrm{dl}$ sebanyak $35.3 \%$; kadar kolesterol HDL $<50 \mathrm{mg} / \mathrm{dl}$ pada pegawai perempuan $5.9 \%$ dan $<40 \mathrm{mg} / \mathrm{dl}$ pada pegawai laki - laki $20.6 \%$; kadar glukosa darah puasa pegawai $\geq 100 \mathrm{mg} /$ dl sebanyak $23.5 \%$; tekanan darah $\geq 130 / 85 \mathrm{mmHg}$ sebanyak $32.4 \%$.

\section{PEMBAHASAN}

Persentase kasus sindrom metabolik yang ditemukan adalah 22.1\%. Hasil ini sesuai dengan penelitian Semiardji (2004) yang menemukan penyakit terkait sindrom metabolik dengan prevalensi sekitar $24.4 \%$ di kalangan pekerja. Hasil ini juga sesuai dengan penelitian International Diabetes Federation (Federation, 2005) yang menyebutkan bahwa prevalensi sindrom metabolik dunia tahun 2006 adalah sebesar 20 - 25\%. Robbi et al. (2016) dengan sampel berusia 25 - 65 tahun berjumlah 300 individu di Jakarta menghasilkan angka prevalensi sindrom metabolik sebesar $21,6 \%$. Penelitian terbaru pada pekerja di Provinsi Riau oleh Zahtamal, Prabandari, \& Setyawati pada tahun 2016 juga menemukan prevalensi kasus sindrom metabolik dengan jumlah yang sejalan, yakni sebesar $21.58 \%$. Namun, hasil yang sedikit berbeda ditemukan dalam penelitian Lohsoonthorn et al. (2007) pada pekerja kantoran di Bangkok, Thailand dengan prevalensi pekerja yang menderita sindrom metabolik adalah sebesar $15.2 \%$. Penyebab utama kematian pekerja adalah penyakit degeneratif dimana penyakit degeneratif tersebut adalah salah satu pemicu sindrom metabolik (Zahtamal, Prabandari, \& Setyawati, 2016).

Tabel 3. Karakteristik Responden Penelitian

\begin{tabular}{|c|c|c|}
\hline Variabel & $\mathrm{n}$ & $\%$ \\
\hline \multicolumn{3}{|l|}{ Umur } \\
\hline $20-30$ & 3 & 20 \\
\hline $31-40$ & 5 & 33.3 \\
\hline $41-50$ & 4 & 26.7 \\
\hline $51-60$ & 3 & 20 \\
\hline \multicolumn{3}{|c|}{ Distribusi Lingkar perut pegawai } \\
\hline \multicolumn{3}{|c|}{ Perempuan } \\
\hline$\geq 88 \mathrm{~cm}$ & 2 & 3.1 \\
\hline$<88 \mathrm{~cm}$ & 3 & 4.5 \\
\hline \multicolumn{3}{|l|}{ Laki - laki } \\
\hline$\geq 102 \mathrm{~cm}$ & 12 & 18.2 \\
\hline$<102 \mathrm{~cm}$ & 49 & 74.2 \\
\hline \multicolumn{3}{|c|}{ Distribusi kadar trigliserida pegawai } \\
\hline$\geq 150 \mathrm{mg} / \mathrm{dl}$ & 24 & 35.3 \\
\hline$<150 \mathrm{mg} / \mathrm{dl}$ & 44 & 65.7 \\
\hline \multirow{2}{*}{\multicolumn{3}{|c|}{$\begin{array}{l}\text { Distribusi kadar kolesterol HDL pegawai } \\
\text { Perempuan }\end{array}$}} \\
\hline & & \\
\hline$\geq 50 \mathrm{mg} / \mathrm{dl}$ & 3 & 4.4 \\
\hline$<50 \mathrm{mg} / \mathrm{dl}$ & 4 & 5.9 \\
\hline \multicolumn{3}{|l|}{ Laki - laki } \\
\hline$\geq 40 \mathrm{mg} / \mathrm{dl}$ & 47 & 69.1 \\
\hline$<40 \mathrm{mg} / \mathrm{dl}$ & 14 & 20.6 \\
\hline \multicolumn{3}{|c|}{ Distribusi kadar glukosa darah puasa pegawai } \\
\hline$\geq 100 \mathrm{mg} / \mathrm{dl}$ & 16 & 23.5 \\
\hline$<100 \mathrm{mg} / \mathrm{dl}$ & 52 & 76.5 \\
\hline \multicolumn{3}{|c|}{ Distribusi tekanan darah pegawai } \\
\hline$\geq 130 / 85 \mathrm{mmHg}$ & 22 & 32.4 \\
\hline$<130 / 85 \mathrm{mmHg}$ & 46 & 67.6 \\
\hline
\end{tabular}

Kelompok usia pegawai yang terbanyak menderita sindrom metabolik adalah 31 - 40 tahun. Hasil ini tidak jauh berbeda dengan penelitian Lohsoonthorn et al. (2007) yang menyebutkan bahwa rerata usia pekerja yang menderita sindrom metabolik sekitar 40 tahun dan semakin bertambah usia pekerja, lebih banyak ditemukan kejadian sindrom metabolik. Hal ini dikarenakan semakin bertambahnya usia kemampuan regulasi energi mengalami penurunan sehingga risiko ketidakseimbangan energi semakin meningkat (Roberts \& Rosenberg, 2006). Hal ini juga didukung oleh Lohsoonthorn, et al (2007) yang menyatakan bahwa semakin bertambah usia pekerja, lebih banyak ditemukan kejadian sindrom metabolik. Jumlah pegawai terbanyak menderita sindrom metabolik adalah pegawai dengan jenis kelamin laki laki. Hasil ini sesuai dengan penelitian Zahtamal, Prabandari, \& Setyawati (2016) yang menyatakan bahwa laki - laki adalah jenis kelamin terbanyak ditemukan pada pekerja yang menderita sindrom metabolik, yakni delapan belas kali lipat dibanding perempuan. Tidak jauh berbeda dari penelitian pada para pekerja di Spanyol, sindrom metabolik masih dominan ditemukan pada laki - laki (Leon et al., 2006). Robbi et al. (2016) juga menemukan prevalensi 
sindrom metabolik pada laki - laki (24.7\%) lebih tinggi dibanding perempuan (11.8\%).

Pada PT Wijaya Karya Divisi IV Surabaya terdapat berbagai posisi pekerjaan yang dapat disederhanakan menjadi dua kategori, yakni di kantor dan di lapangan. Posisi manajer, staf, kepala seksi termasuk dalam kategori lokasi pekerjaan di kantor, sedangkan posisi koordinator, pelaksana, dan lapangan termasuk dalam kategori lokasi pekerjaan di lapangan Pegawai dengan lokasi pekerjaan di dalam kantor lebih banyak menderita sinrom metabolik dengan di lapangan. Hal ini dikarenakan aktivitas fisik teratur dengan tingkat sedang dan berat seperti yang dilakukan para pekerja di lapangan menurunkan risiko untuk terserang sindrom metabolik dibandingkan mereka yang aktivitas fisiknya kurang (sedentary life style) (Laursen et al., 2012). Hasil ini agak berbeda dengan hasil penelitian Leon et al. (2006) yang menyatakan bahwa pekerja manual di lapangan memiliki prevalensi kasus sindrom metabolik lebih besar daripada pekerja di dalam kantor seperti manajer maupun staf.

Seseorang dikatakan menderita sindrom metabolik ketika memiliki tiga penanda sindrom metabolik atau lebih. Sebagian besar pegawai BUMN PT Wijaya Karya Divisi IV Surabaya yang menderita sindrom metabolik memilik jumlah penanda terbanyak yakni 3 komponen. Hasil ini sejalan dengan penelitian Zahtamal, Prabandari, \& Setyawati (2016) yang mengatakan bahwa responden mereka memiliki 3 penanda sindrom metabolik sebagai jumlah penanda terbanyak.

Komponen penanda sindrom metabolik yang pertama adalah lingkar perut. Prevalensi pegawai dengan lingkar perut yang memenuhi kriteria NCEP ATP III adalah $21.3 \%$. Lingkar perut pada penelitian ini merupakan komponen penanda sindrom metabolik dengan persentase paling sedikit dari keseluruhan komponen penanda. Leon et al. (2005) menyatakan hasil yang sedikit berbeda, yakni prevalensi komponen penanda sindrom metabolik dari para pekerja di Spanyol dengan persentase paling sedikit adalah kadar glukosa darah puasa. Dengan bertambahnya usia, jaringan lemak cenderung terakumulasi di daerah perut dengan aktivitas metabolik yang lebih tinggi dengan mengirimkan asam lemak bebas dan sitokin langsung menuju sirkulasi porta dibandingkan lemak subkutan, sehingga meningkatkan risiko terjadinya obesitas abdomen (Aquilante et al., n.d.). Lingkar perut yang semakin besar mendorong peningkatan jaringan lemak tubuh yang menyebabkan adiposit jaringan lemak tersebut lebih mudah dilipolisis dan menghasilkan asam lemak bebas. Tingginya kadar asam lemak bebas dalam tubuh akan memicu pelepasan sitokin, produk produk metabolik yang dapat menurunkan sensitivitas insulin, dan produk dari sel lemak yang bertanggung jawab terhadap berbagai penyakit metabolik (Zahtamal, Prabandari, \& Setyawati, 2016).

Komponen penanda sindrom metabolik yang kedua adalah kadar trigliserida. Jumlah pegawai dengan kadar trigliserida $\geq 150 \mathrm{mg} / \mathrm{dL}$ sebanyak $35.5 \%$. Kadar trigliserida pada penelitian ini adalah komponen sindrom metabolik dengan persentase terbanyak. Hasil ini sedikit berbeda dengan penelitian Zahtamal, Prabandari, \& Setyawati (2016) yang menyatakan bahwa sebagian besar komponen sindrom metabolik yang ditemukan pada para pekerja di
Provinsi Riau adalah lingkar perut. Resistensi insulin lebih lanjut akan meningkatkan lipolisis jaringan adiposa sehingga kadar asam lemak bebas dalam tubuh semakin tinggi. Peningkatan asam lemak bebas akan mendorong terjadinya resistensi insulin pada hepar. Resistensi insulin pada hepar akan meningkatkan kadar trigliserida dalam tubuh (Aquilante et al., nd.).

Komponen penanda sindrom metabolik yang ketiga adalah kadar kolesterol HDL. Prevalensi pegawai dengan kadar kolesterol HDL yang memenuhi kriteria NCEP ATP III adalah 26.5\%. Kadar kolesterol HDL pada penelitian ini merupakan komponen penanda sindrom metabolik dengan persentase pada urutan ketiga terbanyak dari keseluruhan komponen sindrom metabolik. Hasil ini juga sedikit berbeda dengan penelitian Zahtamal, Prabandari, \& Setyawati (2016) yang menyatakan bahwa kadar kolesterol HDL para pekerja di Provinsi Riau adalah komponen sindrom metabolik dengan persentase paling sedikit ditemukan dari keseluruhan komponen. Peningkatan kadar kolesterol HDL dalam tubuh disebabkan oleh resistensi insulin pada hepar (Aquilante et al., n.d.).

Komponen penanda sindrom metabolik yang keempat adalah kadar glukosa darah puasa. Pegawai dengan kadar glukosa darah puasa $\geq 100 \mathrm{mg} / \mathrm{dL}$ sebanyak $23.5 \%$. Kadar glukosa darah puasa dalam penelitian ini adalah komponen penanda sindrom metabolik yang tidak banyak dimiliki para pegawai dengan persentase urutan kedua dari bawah. Hasil ini sesuai dengan dengan temuan Leon et al. (2006) yang menyatakan bahwa kadar glukosa darah puasa merupakan komponen dengan prevalensi paling sedikit $(7.5 \%)$ yang ditemukan pada pekerja di Spanyol. Peningkatan kadar glukosa darah puasa disebabkan oleh resistensi insulin yang berawal dari sinyal kaskade insulin yang terganggu karena tingginya kadar asam lemak bebas dalam tubuh. Asam lemak bebas secara tidak langsung menekan hingga menghilangkan reseptor insulin pada sel (Stocker \& Keaney, 2004). Kerja insulin yang terhambat akan menginduksi pankreas untuk mensekresi insulin lebih banyak agar kesimbangan gukosa tubuh terjaga. Namun semakin lama pankreas tidak lagi mampu mensekresi insulin dalam jumlah yang cukup karena sebanyak apapun insulin yang diproduksi tidak dapat digunakan dengan semestinya oleh tubuh (Aquilante et al., n.d.).

Komponen penanda sindrom metabolik yang terakhir adalah tekanan darah. Pegawai dengan tekanan darah $\geq 130 / 85 \mathrm{mmHg}$ sebanyak $32.4 \%$. Tekanan darah dalam penelitian ini adalah komponen penanda sindrom metabolik dengan prevalensi terbanyak kedua dari keseluruhan komponen penanda. Zahtamal, Prabandari, \& Setyawati (2016) juga menemukan bahwa tekanan darah tinggi merupakan komponen penanda sindrom metabolik dengan prevalensi terbanyak kedua. Resistensi insulin dan hiperinsulinemia berhubungan dengan overeaktivitas pada system syaraf simpatis. Respon syaraf simpatis yang berlebih akan meningkatkan reabsorbsi Natrium pada ginjal dan menurunkan efek vasodilatasi, di mana keadaan tersebut dapat berkontribusi dalam terjadinya hipertensi pada penderita sindrom metabolik (Aquilante et al., n.d.).

Penelitian ini memiliki beberapa keterbatasan 
di dalam proses pembuatannya. Beberapa data dari dokumen medis hasil pemeriksaan kesehatan para pegawai pada bulan Oktober 2016 tidak lengkap, sehingga sampel yang memenuhi kriteria dan dapat digunakan dalam penelitian menjadi lebih sedikit. Jumlah sampel penelitian berkurang akibat dokumen medis hasil pemeriksaan kesehatan pegawai yang tersedia hanya dari divisi IV PT Wijaya Karya di Surabaya sehingga prevalensi dan distribusi pada penelitian ini kurang memberikan hasil yang diinginkan.

\section{KESIMPULAN}

Prevalensi sindrom metabolik yang ditemukan adalah $22.1 \%$ dengan laki - laki sebagai jenis kelamin terbanyak (93.3\%) dan kelompok usia terbanyak adalah 31 - 40 tahun (33.3\%). Pekerja di dalam kantor memiliki prevalensi lebih besar $(66.7 \%)$ daripada pekerja lapangan. Jumlah penanda sindrom metabolik menurut kriteria NCEP ATP III yang terbanyak ditemukan adalah 3 penanda $(66.7 \%)$ dengan urutan dari yang terbanyak ditemukan adalah kadar trigliserida $(35.5 \%)$, tekanan darah $(32.4 \%)$, kadar kolesterol HDL (26.5\%), kadar glukosa darah puasa $(23.5 \%)$ dan lingkar perut $(21.3 \%)$.

\section{DAFTAR PUSTAKA}

American Heart Association. (2015). What is Metabolic Syndrome? Fact Sheet.

Aquilante, C. L., Pharm, D., Griend, J. P. Vande, Pharm, D., Cardiology, A. Q., Parra, D., ... Cardiology, B. A. Q. (n.d.). Pharmacotherapy Self-Assessment Program, 6th Edition 109 Metabolic Syndrome Learning Objectives. https://doi.org/http://dx.doi.org/10.1002/ nau. 21185

Barzilai, N., Huffman, D. M., Muzumdar, R. H., \& Bartke, A. (2012). The critical role of metabolic pathways in aging. Diabetes, 61(6), 1315-1322. https://doi.org/10.2337/db111300

Federation, I. D. (2005). Full-Text.

Freeman, J. T., Ph, D., \& Freeman, C. J. (2002). 2002 Command and Control Research and Technology Symposium Topic: C2 Decision Making \& Cognitive Analysis Team Collaboration for Command and Control : A Critical Thinking Model Team Collaboration for Command and Control : A Critical Thinking, 316(October 2006), 362-367.

Gami, A. S., Witt, B. J., Howard, D. E., Erwin, P. J., Gami, L. A., Somers, V. K., \& Montori, V. M. (2007). Metabolic Syndrome and Risk of Incident Cardiovascular Events and Death. A Systematic Review and Meta-Analysis of Longitudinal Studies. Journal of the American College of Cardiology, 49(4), 403-414. https://doi.org/10.1016/j.jacc.2006.09.032

Guyton, A.C. \& Hall, J.E. (2006). Energi dan Laju Metabolik. Dalam Buku Ajar Fisiologi Kedokteran. Edisi 11. Jakarta. EGC, 881 887.

Hildrum, B., Mykletun, A., Hole, T., Midthjell, K., \& Dahl, A. A. (2007). Age-specific prevalence of the metabolic syndrome defined by the International Diabetes Federation and the National Cholesterol Education Program: The
Norwegian HUNT 2 study. BMC Public Health, 7, 1-9. https://doi.org/10.1186/14712458-7-220

International Labour Organization. (2013). The Prevention of Occupational Diseases - World Day for safety and health at work 28 April 2013., (April).

Karimi, F., Jahandideh, D., Dabbaghmanesh, M., Fattahi, M., \& Omrani, G. R. (2015). The prevalence of metabolic syndrome and its components among adults in a rural community, Fars, Iran. International Cardiovascular Research Journal, 9(2), 94-99.

Lohsoonthorn, V., Lertmaharit, S., \& Williams, M. A. (2007). Prevalence of metabolic syndrome among professional and office workers in Bangkok, Thailand. Journal of the Medical Association of Thailand, 90(9), 1908-1915.

Lorenzo, C., Okoloise, M., Williams, K., Stern, M. P., Haffner, S. M., \& San Antonio Heart Study. (2003). The Metabolic Syndrome as Predictor of Type 2 Diabetes. Diabetes Care, 26(11), 3153-3159. https://doi.org/10.2337/ DIACARE.26.11.3153

Report, F. (1999). Final Report. Materials and Structures, 32(3), 163-173. https:// doi.org/10.1007/BF02481509

Robbi, Y. K., Juwita, R., Besral, B., Lubis, D. U., Kamso, S., \& Purwantyastuti, P. (2016). Prevalensi dan Determinan Sindrom Metabolik pada Kelompok Eksekutif di Jakarta dan Sekitarnya. Kesmas: National Public Health Journal, 6(2), 85. https:// doi.org/10.21109/kesmas.v6i2.110

Roberts, S. B., \& Rosenberg, I. (2006). Nutrition and Aging: Changes in the Regulation of Energy Metabolism With Aging. Physiological Reviews, 86(2), 651-667. https:// doi.org/10.1152/physrev.00019.2005

Semiardji, G. (2004). The Prevalence of the Metabolic Syndrome: Findings from the Epidemiology Study on Obesity and Its Comorbifities in Indonesian Population, dalam: Tjokroprawiro, A., Soegih, R., Soegondo, S., Wijaya, A., Sutardjo, B., Tridjaja, B., et al. Proceedings of the 3 National Obesity Symposium, Jakarta: Indonesian Society for the Study on Obesity.

Stocker, R., \& Keaney, J. F. (2004). Role of Oxidative Modifications in Atherosclerosis. Physiological Reviews, 84(4), 1381-1478. https://doi.org/10.1152/physrev.00047.2003

Sugiyono. (2007). Metode Penelitian Pendidikan Pendekatan Kuantitatif, Kualitatif, dan $R \& D$. Bandung:ALFABETA

Zahtamal, Z., Prabandari, Y. S., \& Setyawati, L. (2016). Prevalensi Sindrom Metabolik pada Pekerja Perusahaan. Kesmas: National Public Health Journal, 9(2), 113. https:// doi.org/10.21109/kesmas.v9i2.499 